Article

\title{
Executive Functions, Motor Development, and Digital Games Applied to Elementary School Children: A Systematic Mapping Study
}

Victória Branca Moron ${ }^{1, *}$, Débora Nice Ferrari Barbosa ${ }^{1, * \mathbb{D}}$, Gustavo Roese Sanfelice ${ }^{1} \mathbb{D}$, Jorge Luis Victória Barbosa ${ }^{2} \mathbb{D}$, Daiana R. F. Leithardt ${ }^{3}$ (D) and Valderi Reis Quietinho Leithardt ${ }^{4,5}$ (D)

Citation: Moron, V.B.; Barbosa,

D.N.F.; Sanfelice, G.R.; Barbosa, J.L.V.;

Leithardt, D.R.F.; Leithardt, V.R.Q

Executive Functions, Motor Development, and Digital Games Applied to Elementary School Children: A Systematic Mapping Study. Educ. Sci. 2022, 12, 164. https://doi.org/10.3390/

educsci12030164

Academic Editors: James Albright and Stephen A. Butterfield

Received: 28 October 2021

Accepted: 24 February 2022

Published: 27 February 2022

Publisher's Note: MDPI stays neutral with regard to jurisdictional claims in published maps and institutional affiliations.

Copyright: (c) 2022 by the authors. Licensee MDPI, Basel, Switzerland. This article is an open access article distributed under the terms and conditions of the Creative Commons Attribution (CC BY) license (https:// creativecommons.org/licenses/by/ $4.0 /)$.
1 Cultural Diversity and Social Inclusion Graduate Program, Feevale University, ERS-239, 2755, Novo Hamburgo 93525-075, Brazil; sanfeliceg@feevale.br

2 Applied Computing Graduate Program, University of Vale do Rio dos Sinos, Av. Unisinos 950, São Leopoldo 93022-750, Brazil; jbarbosa@unisinos.br

3 Departamento de Química, Faculdade de Ciências, Universidade da Beira Interior, R. Marquês d'Ávila e Bolama, 6201-001 Covilhã, Portugal; daiana.leithardt@ubi.pt

4 COPELABS, Universidade Lusófona de Humanidades e Tecnologias, 1749-024 Lisboa, Portugal; valderi@ipportalegre.pt

5 VALORIZA, Research Center for Endogenous Resources Valorization, Instituto Politécnico de Portalegre, 7300-555 Portalegre, Portugal

* Correspondence: vbmoron@feevale.br(V.B.M.); deboranice@feevale.br (D.N.F.B.)

\begin{abstract}
Studies show that executive functions and motor development are associated with each other and with learning ability. A more technological lifestyle combined with digital culture should be considered a viable alternative to stimulate children's development. Therefore, this study aimed to present a systematic mapping of the literature involving executive functions, motor development, and the use of digital games in intervention programs for elementary school children from 6 to 11 years old. Four databases were researched: PubMed, Scielo, Science Direct, and SCOPUS, including publications between 2012 and March 2021. The initial results indicated 4881 records. After the selection process, 15 manuscripts that presented the central theme of the study were selected. The main results indicated that intervention strategies are rather heterogeneous. Most of the studies demonstrated efficient results after intervention protocols, many of them were conducted in Europe, and $46 \%$ occurred in a school environment. No research was identified involving technological solutions using executive functions, motor development, and digital games in an integrated manner. Hence, this constitutes a field of future scientific research.
\end{abstract}

Keywords: cognition; intervention program; motor skills; video game

\section{Introduction}

The development of motor skills is not typically considered a cognitive component; however, the "motor" issue implies cognition as the performance of physical movements necessary for learning requires planning and deliberation [1]. The development of motor skills enables children to perform goal-oriented movements and behaviors [2]. Executive functions, in turn, control and regulate behavior to achieve specific goals. They are essential for the child to have more autonomy, emotional independence, and action planning [3]. In this case, many studies have investigated the association between motor and cognitive development, particularly executive functions [4]. A more technological lifestyle associated with digital culture should be considered a viable alternative to stimulate cognitive and motor children development $[5,6]$. Indeed, technology in contemporary society is a reference in the dimension of leisure, work, and knowledge [7]. Therefore, this work aims to understand the relationships between motor and cognitive development associated with 
the use of digital technologies, mainly digital games, based on a systematic mapping of the literature.

Executive functions are divided into several components. According to Diamond [8], the basic ones are working memory, cognitive flexibility, and inhibitory control. Components of a higher order stem from those: working memory (decision making, problemsolving, selective attention, perceptual speed, anticipation, and prediction); cognitive flexibility (planning and sequencing, spatial orientation, capacity for abstraction, problems, and decomposition); and inhibitory control (selective attention, sustained attention, capacity to inhibit, resistance to interference, and classifying).

The relationship between motor skills and executive functions is often explained by overlapping brain areas important to both abilities. Neural networks, including the frontal, parietal, and motor cortex, are not only involved in underlying executive functions, but also motor tasks. In addition, the cerebellum and basal ganglia, crucial for motor skills, are also involved in executive functions [9].

At the behavioral level, the connection between motor skills and cognitive functions is explained by the involvement of executive functions in motor tasks [10]. Executive functions and motor skills are fundamental for the child's development. These two components provide a foundation for long-term academic success and co-development in young children involving bidirectional and synergistic aspects. The theoretical development comes from the perspectives of the dynamic system, which considers the development of children as multilevel, interactive, and bidirectional [11].

A child with proper cognition and motor development tends to become a young adult who learns better and has a better quality of life. This means that by conquering well motor control and executive function developments, the child will be building the basics for his/her intellectual development, preventing him/her from having an impairment of motor and cognitive abilities [11]. The stimulation of motor and cognitive development involves biological and maturational factors. This process varies according to the speed of progression among children, even though the motor development sequence is the same for everyone. Today, we need to deal with technologies and understand that development processes are involved in different contexts. Digital games represent a technological element that is part of digital culture, into which children are inserted [12]. Digital games are tools that promote the engagement and interaction of children and adolescents with digital artifacts. As a result, research is being performed involving the use of digital games to stimulate motor development [13] and executive functions [14].

The use of digital games enables cognitive stimulation in a playful and natural context for children, considering an ecological approach. It considers the daily tasks that the individual practices or the context and environment in which they are inserted. In this perspective, there is a tendency to integrate ecological theories into several applications in neuropsychological science [15] and the evaluation of motor development in children [16]. In the area of motor development, it is possible to combine bodily activities with activities from digital games. In this context, there is a cognitive theory in which the intellectual understanding of concepts is reinforced by bodily interactions with the physical world. This theory suggests that "embedded interactions" can stimulate the development of students' cognitive processes. In addition, it helps to understand abstract theoretical concepts through experience, exploration, and practice of controlled body movements [17].

Studies have strived to understand and propose interventions that assess and/or promote motor and executive development [18]. Still, research involves interventions stimulating executive functions mediated by technologies [19]. These interventions can take place in different contexts and involve different methodologies. Nevertheless, the school context is configured as an important environment, as it is part of the child's daily life, allowing interventions in an ecological approach. This approach assesses the child globally and naturally, considering his/her time and space and not just within specific conditions [20]. 
Hence, considering the presented context, this paper investigates recent studies related to executive function and motor development through digital games. The study has two main purposes: (1) to evaluate the methodologies employed in the assessment of the interventions, and (2) to verify the strategies to conduct the school intervention program. This research presents the results of a systematic mapping of the literature that analyzes studies involving executive functions, motor development, and the use of digital games in intervention programs for elementary school children from 6 to 11 years old.

This paper is organized as follows: the Methods section demonstrates the methodology used and states the questions pertinent to the systematic mapping of the literature proposed here. The Results and Discussion section presents the results of the research in the databases, the findings on the previously raised issues. Finally, the Conclusion section addresses the main outcomes of the study.

\section{Methods}

This study is based on the methodological process of systematic mapping, proposed by Peterson et al. [21], consisting of four distinct steps: (1) definition of research questions; (2) delimitation of the research process; (3) definition of criteria for filtering results; and (4) classification of results for further analysis.

\subsection{Research Questions}

The research process was based on three groups of questions: general questions (GQ), focal questions (FQ), and statistical questions (SQ), which were categorized as per Table 1.

Table 1. Research questions.

\begin{tabular}{cc}
\hline ID & Questions \\
GQ1 & What were the strategies used to conduct the intervention program? \\
GQ2 & What were the results of intervention programs involving executive functions and \\
motor development?
\end{tabular}

\subsection{Research Process}

The process used to define the strings was based on specific keywords. Initially, a broad investigation was performed, involving the following terms and their synonyms together: executive function, motor development, digital game, and children.

However, the findings were not satisfactory, as no studies involving the terms executive functions, motor development, and digital games together were found. Therefore, to expand the results, the research was divided into three groups: (1) executive functions and motor development; (2) executive functions and digital games; and (3) motor development and digital games. Thus, we sought to identify a higher number of studies, so that in the analysis process, a relationship between the findings involving the three study variables could be made. This process originated the following research strings used in this study:

Group 1: ("executive function" OR "cognition") AND ("motor development" OR "motor skill") AND ("children" OR "childhood")

Group 2: ("executive function" OR "cognition") AND ("video game" OR "digital game" OR "digital technology" OR "software" OR "mobile device" OR "computer") AND ("children" OR "childhood") 
Group 3: ("motor development" OR "motor skill") AND ("video game" OR "digital game" OR "digital technology" OR "software" OR "mobile device") AND ("children" OR "childhood").

The research strings were applied to four databases: PubMed (https:/ / pubmed.ncbi.nlm. nih.gov / (accessed on 05 August 2021)), Scielo (https:/ / scielo.org/ (accessed on 5 August 2021)), Science Direct (https:/ / www.sciencedirect.com/ (accessed on 6 August 2021)), and SCOPUS (https://www.scopus.com/home.uri (accessed on 6 August 2021)), and included records published between 2012 and 2021. Among those, PubMed is known for being a literature database in the health area. The other databases were inserted in the research as they encompass a wide variety of periodicals in other fields. Mapped articles were stored using the tool Rayyan (https:/ /www.rayyan.ai/ (accessed on 5 August 2021)). Subsequently, they were exported for bibliometric analysis at VOSViewer (https:/ / www.vosviewer.com/ (accessed on 30 September 2021)).

\subsection{Filter of Results and Data Extraction}

The following inclusion criteria (IC) were defined to filter the research results:

(IC1)_Articles published from 2012 to March 2021;

(IC2)-Publications in conferences, journals, or workshops;

(IC3) - Complete and full access to content; and

(IC4)-Publication which involves children in typical development from elementary school from 6 to 11 years old.

In contrast, the following exclusion criteria (EC) were defined for the second round of filtering:

(EC1) -Duplicated articles;

(EC2) - Theses, dissertations, books, and reviews; and

(EC3)-Articles unrelated to the theme.

Figure 1 represents the research process, which utilized the defined string on the databases publications for title, abstract, and keywords. Consequently, singular and plural keywords were used in the research string for each database, producing the initial results. Afterward, filters EC1, EC2, and EC3 were applied. Subsequently, Keshav's [22] three-step technique was adopted: (1) reading the title, abstract, and introduction, analyzing the titles of sections and subsections, mathematical elements (if any), and conclusions. During this first step, the exclusion criteria (EC3) were applied, since they were adherent to this part of the process, by reading all sections and subsections of the articles. After the first step, the other two were carried out: (2) analysis of figures, diagrams, or illustrations and (3) the initial analysis of the databases research found a total of 44,010 publications. From these, pre-selection included 49 publications for being in the thematic area, among which the final selection encompassed 15.

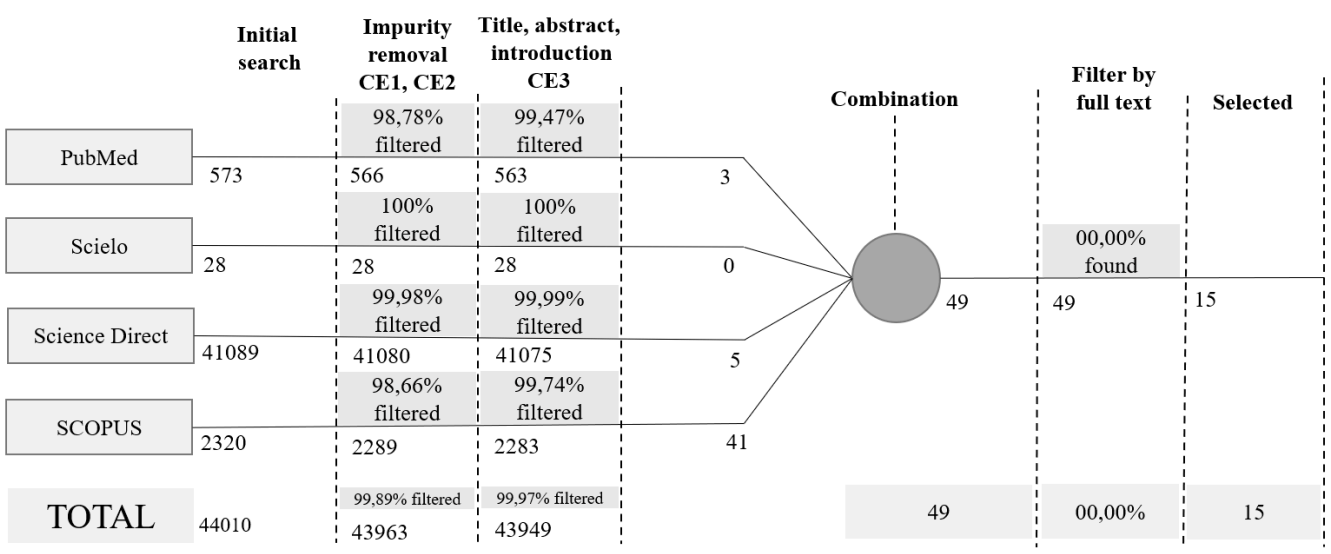

Figure 1. Steps in the research process. 


\section{Results and Discussion}

Table 2 presents the articles organized by authors and year of publication, title, sample $(\mathrm{N})$, age, database, H-index, country, research duration, and research focus (EF: executive function; MD: motor development; DG: digital game). The criteria used to organize the studies in the table were the year of publication followed by the focus of the research (first EF + MD, then, EF + DG, and MD + DG). The results for each research question are presented below. Considering that this study aims to identify the current scenario of research involving executive functions, motor development, and digital games, the research process involved articles from conferences, journals, or workshops (IC2), according to the methodology used for systematic review. All included studies, which resulted from the research process, were published in journals.

Table 2. List of mapped articles.

\begin{tabular}{|c|c|c|c|c|c|c|c|c|}
\hline Authors (Year) & Title & $\mathbf{N}$ & Age & Database & H-Index & Country & Duration & Research \\
\hline $\begin{array}{l}\text { Alesi et al. } \\
\text { (2014) [23] }\end{array}$ & $\begin{array}{l}\text { Motor and cognitive } \\
\text { development: The role } \\
\text { of karate }\end{array}$ & 39 & 9 years old & PubMed & 32 & Italy & 2 weeks & $\mathrm{EF}+\mathrm{MD}$ \\
\hline $\begin{array}{l}\text { Wunsch et al. } \\
\text { (2016) [24] }\end{array}$ & $\begin{array}{l}\text { No interrelation of motor } \\
\text { planning and executive } \\
\text { functions across } \\
\text { young ages }\end{array}$ & 217 & $3-10$ years old & SCOPUS & 95 & Germany & 1 session & $\mathrm{EF}+\mathrm{MD}$ \\
\hline $\begin{array}{l}\text { Egger et al. } \\
\text { (2018) [25] }\end{array}$ & $\begin{array}{l}\text { The effect of acute } \\
\text { cognitively engaging } \\
\text { physical activity breaks } \\
\text { on children's executive } \\
\text { functions: Too much of a } \\
\text { good thing? }\end{array}$ & 216 & 7-9 years old & Science Direct & 93 & Switzerland & 1 session & $\mathrm{EF}+\mathrm{MD}$ \\
\hline $\begin{array}{c}\text { Haapala et al. } \\
\text { (2019) [26] }\end{array}$ & $\begin{array}{l}\text { Longitudinal associations } \\
\text { of fitness, motor } \\
\text { competence, and } \\
\text { adiposity with cognition }\end{array}$ & 371 & 6-9 years old & SCOPUS & 216 & Finland & 2 years & $\mathrm{EF}+\mathrm{MD}$ \\
\hline $\begin{array}{c}\text { Ludyga et al. } \\
\text { (2019) [27] }\end{array}$ & $\begin{array}{l}\text { A randomized controlled } \\
\text { trial on the effects of } \\
\text { aerobic and coordinative } \\
\text { training on neural } \\
\text { correlates of inhibitory } \\
\text { control in children }\end{array}$ & 45 & 9-10 years old & PubMed & 99 & Germany & 10 weeks & $\mathrm{EF}+\mathrm{MD}$ \\
\hline $\begin{array}{l}\text { Van Der Fels } \\
\text { et al. (2019) [28] }\end{array}$ & $\begin{array}{l}\text { Relations between gross } \\
\text { motor skills and } \\
\text { executive functions, } \\
\text { controlling for the role of } \\
\text { information processing } \\
\text { and lapses of attention in } \\
8-10 \text { year old children }\end{array}$ & 732 & $8-10$ years old & SCOPUS & 300 & Netherlands & 2 weeks & $\mathrm{EF}+\mathrm{MD}$ \\
\hline $\begin{array}{l}\text { Lin et al. } \\
\text { (2021) [29] }\end{array}$ & $\begin{array}{l}\text { Up-regulation of } \\
\text { proactive control is } \\
\text { associated with beneficial } \\
\text { effects of a childhood } \\
\text { gymnastics program on } \\
\text { response preparation and } \\
\text { working memory }\end{array}$ & 48 & $7-10$ years old & Science Direct & 122 & Taiwan & 8 weeks & $\mathrm{EF}+\mathrm{MD}$ \\
\hline $\begin{array}{l}\text { Rudd et al. } \\
\text { (2021) [30] }\end{array}$ & $\begin{array}{l}\text { Comparing the efficacy } \\
\text { (RCT) of learning a dance } \\
\text { choreography and } \\
\text { practicing creative dance } \\
\text { on improving executive } \\
\text { functions and motor } \\
\text { competence in } 6-7 \text { years } \\
\text { old children }\end{array}$ & 62 & 6-7 years old & Science Direct & 97 & Australia & 8 weeks & $\mathrm{EF}+\mathrm{MD}$ \\
\hline $\begin{array}{l}\text { Mondéjar et al. } \\
\text { (2016) [31] }\end{array}$ & $\begin{array}{l}\text { Correlation between } \\
\text { videogame mechanics } \\
\text { and executive functions } \\
\text { through EEG analysis }\end{array}$ & 12 & $8-12$ years old & PubMed & 91 & Spain & 1 session & $\mathrm{EF}+\mathrm{DG}$ \\
\hline
\end{tabular}


Table 2. Cont.

\begin{tabular}{|c|c|c|c|c|c|c|c|c|}
\hline Authors (Year) & Title & $\mathbf{N}$ & Age & Database & H-Index & Country & Duration & Research \\
\hline $\begin{array}{l}\text { Sánchez-Pérez } \\
\text { et al. (2018) [32] }\end{array}$ & $\begin{array}{l}\text { Computer-based training } \\
\text { in math and working } \\
\text { memory improves } \\
\text { cognitive skills and } \\
\text { academic achievement in } \\
\text { primary school children: } \\
\text { Behavioral results }\end{array}$ & 104 & $7-10$ years old & SCOPUS & 95 & Spain & 13 weeks & $\mathrm{EF}+\mathrm{DG}$ \\
\hline $\begin{array}{l}\text { Özçetin et al. } \\
\text { (2019) [33] }\end{array}$ & $\begin{array}{l}\text { The relationships } \\
\text { between video game } \\
\text { experience and cognitive } \\
\text { abilities in adolescents }\end{array}$ & 52 & 10-16 years old & SCOPUS & 62 & Turkey & 1 year (min.) & $\mathrm{EF}+\mathrm{DG}$ \\
\hline $\begin{array}{l}\text { Song et al. } \\
(2020)[34]\end{array}$ & $\begin{array}{l}\text { Validation of a mobile } \\
\text { game-based assessment } \\
\text { of cognitive control } \\
\text { among children } \\
\text { and adolescents }\end{array}$ & 100 & 9-16 years old & SCOPUS & 300 & South Korea & Not given & $\mathrm{EF}+\mathrm{DG}$ \\
\hline $\begin{array}{l}\text { Sheeran et al. } \\
\text { (2013) [35] }\end{array}$ & $\begin{array}{l}\text { The effects of a daily, } \\
\text { 6-week exergaming } \\
\text { curriculum on balance in } \\
\text { fourth grade children }\end{array}$ & 64 & $\begin{array}{l}4^{\text {a }} \text { grade } \\
\text { students }\end{array}$ & Science Direct & 30 & Canada & 8 weeks & $\mathrm{MD}+\mathrm{DG}$ \\
\hline $\begin{array}{l}\text { Barnett et al. } \\
\text { (2015) [36] }\end{array}$ & $\begin{array}{l}\text { Playing active video } \\
\text { games may not develop } \\
\text { movement skills: An } \\
\text { intervention trial }\end{array}$ & 95 & $4-8$ years old & Science Direct & 24 & Australia & 6 weeks & $\mathrm{MD}+\mathrm{DG}$ \\
\hline $\begin{array}{l}\text { McGlashanN } \\
\text { et al. (2017) [37] }\end{array}$ & $\begin{array}{l}\text { Improvement in } \\
\text { children's fine motor } \\
\text { skills following a } \\
\text { computerized typing } \\
\text { intervention }\end{array}$ & 28 & 8-10 years old & Science Direct & 86 & $\begin{array}{l}\text { United } \\
\text { Kingdom }\end{array}$ & 4 weeks & $\mathrm{MD}+\mathrm{DG}$ \\
\hline
\end{tabular}

During the analysis, special attention was given to mapping possible relationships among articles involving executive functions, motor development, and digital games since the research string was fragmented. However, it is possible to notice that the selected articles refer mainly to interventions related to executive functions and motor development (54\%).

\subsection{GQ1-What Were the Strategies Used to Conduct the Intervention Program?}

In this question, the general design of the studies was analyzed. The aspects of executive functions, motor development, and digital games were presented, in pairs and in general. The type of analysis, the period and/or duration of the interventions, the application of tests, the type and number of experimental and control groups, if applicable, were identified.

One study (6\%) used a non-randomized controlled design [29] and three (20\%) used a randomized controlled design $[27,28,30]$. Three $(20 \%)$ were experimental [23-25], two longitudinal (14\%) [26,32], one (6\%) performed the cross-sectional design [32], and five (33\%) studies did not disclose which design was used [31,35-37].

\subsubsection{Executive Functions and Motor Development}

The study by Alesi et al. [23] compared the motor skills (sprint, coordination, and explosive leg strength) and the basic executive functions in children. Participants were divided into two groups, karate practitioners and sedentary groups. Skills were measured by motor and cognitive tests. Anthropometric and motor measurements were performed in one session and cognitive assessments in another. The second session lasted 2 weeks.

Regarding the development of motor planning and executive functioning in children, the research by Wunsch et al. [24] evaluated participants who were tested using three motor tasks and three cognitive tasks. Children were separated into 1-year age groups. The examiner individually tested participants. The sessions lasted an average of 90 to $100 \mathrm{~min}$.

Considering the coordination and aerobic capacity, the study by Egger et al. [25] compared the separate and/or combined acute effects of physical exertion and cognitive 
involvement induced by physical activity in the classroom, in children's executive functions. The study was conducted in one intervention session. Participants were randomly divided into intervention groups: combo group (high cognitive involvement and high physical effort); cognition group (cognitive involvement and low physical effort); aerobic group (low cognitive involvement and high physical effort); and control group (low cognitive involvement and low physical effort). Executive functions were measured before and immediately after a 20-min intervention. To test the successful manipulation of cognitive engagement and physical exertion, heart rate, perceived exertion, and perceived cognitive engagement were assessed. Information on academic performance, aerobic fitness, and gross motor skills were collected independently $2-4$ weeks after the intervention.

The research by Haapala et al. [26] investigated the longitudinal associations of cardiorespiratory fitness, motor competence, and body fat percentage with cognition in children. Over two years, the maximum cycle ergometer test, motor competence tests, fat percentage measurement, and cognitive assessment tests were performed.

As for coordination ability, the study by Ludyga et al. [27] compared the effects of aerobic and coordinative training on behavioral and neurophysiological measures considering inhibitory control. This study was conducted by groups that performed aerobic training, coordination training, or assisted homework sessions for 10 weeks. Inhibitory control and aerobic and coordinative capacity were evaluated using specific tests. During the data collection, outcome evaluators were blinded for the participants group allocation. In the intervention period, the number of physical education classes was identical among groups ( $3 \times 45 \mathrm{~min}$ per week). In addition, both intervention groups completed a training program, which consisted of three 45-min sessions per week, during leisure time (after school). An instructor with experience in aerobics and coordination training with children supervised these sessions.

In the research by Van Der Fels et al. [28], the link between gross motor skills and aspects of executive functioning was investigated. Furthermore, the role of information processing and attention lapses in the relationship between motor skills and executive functions was analyzed. The children in this study were part of a project called "Learning in Motion". This project evaluated the effects of two physical activity interventions on physical and cognitive outcomes, academic performance, brain structure, and brain function. Gross motor skills were assessed during one or two physical education classes in a circuit form. Executive functioning tasks were evaluated in a quiet room at the children's school. Trained examiners individually tested the children. The tests were evaluated in two parts over two days.

The study by Lin et al. [29] focused on the effect of an 8-week physical program with gymnastics activities. The activities were based on motor skills and variation from eventrelated brain potentials during a working memory task. The gymnastics group engaged in a gymnastics program. Children in the control group maintained their typical routine during the intervention period. The performance of working memory and motor skills were assessed using specific tests.

The research by Rudd et al. [30] examined the effect of two dance curricula on the executive functions and motor competence of elementary school children. One was a dance curriculum that emphasized creativity, and the other was based on choreographed dance with a high level of cognitive demand. The intervention lasted 8 weeks, twice a week. Executive functions and motor competence were assessed at three moments (baseline, pre-intervention, and post-intervention).

\subsubsection{Executive Functions and Digital Games}

The study by Mondéjar et al. [31] analyzed the activities of the brain's frontal lobe. The analyses took place during a psychological assessment and while the participants played. The experiment was divided into two stages, based on psychological and video game-based assessments. The analysis was performed by collecting brain signals during the two stages of the experiment. Signals were analyzed with a neuroheadset electroencephalogram. 
Also considering school performance, the study by Sánchez-Pérez et al. [32] examined the effectiveness of computer-based school training. The training consisted of two components, working memory and math tasks. The study followed three phases, pre-training, training, and post-training. The pretest lasted approximately 3 weeks and was followed by 13 weeks of training for the experimental group. One week after ending the training period, children in both groups were reassessed. To assess the effects of training, executive functions, IQ, grades, and math and reading skills were measured. For this purpose, standardized tests, math, and language scores were used.

The research by Özçetin et al. [33] evaluated the effect of commercial video games on the executive functions of children and adolescents. Volunteer participants were chosen after an IQ test and an initial interview. The selected participants regularly played video games for at least $1 \mathrm{~h}$ a day, 5 days a week, for at least a year. The players had their executive functions evaluated through neuropsychological tests. Data such as demographics, medical, and video game types were collected through questionnaires.

The study by Song et al. [34] assessed cognitive control through a cell phone game and compared it with the results from traditional neuropsychological tests. They observed relationships among the various gaming behavior scores, neuropsychological tests, and a self-reported executive function difficulty questionnaire.

\subsubsection{Motor Development and Digital Games}

The research by Sheehan et al. [35] used a purpose-built exergame center in a school. The intent was to test fourth graders with an exergame curriculum designed to improve postural stability. The program was implemented over 6 weeks, for 34 min a day, 4-5 days a week. Three groups were observed, one intervention and two control groups (1-physical education focused on agility, balance, and improvement of coordination, 2-a typical curriculum of physical education class). The assessments were carried out through a platform for balance tests.

Another study also used exergames. However, Barnett et al. [36] investigated the impact of active video games on children's actual and perceived object control skills. Children in the intervention group played the exergame $6 \mathrm{~h}$ a week for 6 weeks after school hours. Assessments were carried out for the object control competence and a valid pictorial instrument for the perceived object control competence.

Finally, the research by McGlashan et al. [37] explored whether an online interactive typing intervention could improve children's scores for manual dexterity. This study also implemented a serial touch reaction time task as an index of children's finger learning. The intent was to see if performance on this task would improve after the intervention. Children in the intervention group played at home for 4 weeks. The control group did not play any games. Standardized tests were used to measure serial reaction time, motor, and educational performance.

\subsubsection{General Analysis}

Regarding the executive functions of the twelve studies, eight analyzed them in general [23,25,26,30-34], one study only the inhibitory control [27], another considered only the working memory [29], one the inhibitory control and working memory [28], and one did not specify [24].

Out of the eleven studies on motor development, two considered gross motor skills in general [28,29], one object control ability [36], one manual dexterity [31], three considered coordination [23,25,27], one balance [29], one motor planning [24], and two observed motor competence $[26,30]$.

The average time of application of interventions was 3.5 months. The shortest applications lasted 1 session, the longest 2 years, and one study did not disclose the duration.

Nine studies $(60 \%)$ performed pre- and post-tests. One of the studies, with a longitudinal design, had tests performed over the 2 years of intervention [26].

Three studies (20\%) recorded electroencephalographic (EEG) activity [27,29,31]. 
Six studies (40\%) used an intervention group and a control group [23,26,29,32,36,37], one study $(6 \%)$ used two intervention groups [30], one study (6\%) used two intervention groups and a control group [27], one study $(6 \%)$ used three intervention groups and a control group [25], one study (6\%) used eight intervention groups and an additional adult group [19], and one study (6\%) used two control groups and an experimental group [35].

Strategies to conduct the intervention programs are heterogeneous. It is not possible to establish a pattern among the applications of the studies, whether regarding the researched variables, the types of groups, or the duration of the interventions.

\subsection{GQ2-What Were the Results of Intervention Programs Involving Executive Functions and Motor Development?}

Eight studies presented results related to executive functions and motor development. In the research by Alesi et al. [23], they found significant differences between children who practice karate and sedentary children. The karate practitioners had better speed time, explosive leg strength, and coordination skills. Furthermore, they scored better on working memory and selective visual attention.

In Wunsch et al. [24], the older the children were, the better was their performance. Performance on separate tasks was not correlated among participants in different age groups. In addition, there was no association between performance on the motor and cognitive tasks used in the age control.

In the study by Egger et al. [25], the results demonstrated a significant negative effect on cognitive involvement in the executive function of cognitive flexibility. No effects were found on working memory or inhibitory control. No significant effects were found for physical effort or the interaction between physical effort and cognitive involvement. Thus, the results indicated that an acute session of cognitive involvement in physical activity in the classroom could deteriorate children's cognitive performance.

The results of Haapala et al. [26] demonstrated that higher motor competence at baseline predicts better cognition during the first 2 years of schooling in boys but not in girls. Furthermore, cardiorespiratory fitness and adiposity were not associated with cognition in both sexes.

The research by Ludyga et al. [27] found no significant differences. However, the results indicated that such training programs have no negative influence on the inhibitory aspect of executive functions. Aerobic and coordination training led to an improvement in cardiovascular fitness.

In the findings of Van Der Fels et al. [28], lapses of attention were related to all executive functions while processing speed. After controlling the processing of information and attention spans, gross motor skills were specifically related to visuospatial working memory and response inhibition. The results indicated that gross motor skills are related to aspects of executive functions that are more directly involved and share common underlying processes.

In the intervention by Lin et al. [29], the results showed significant improvements in motor skills and working memory between the pre- and post-tests.

In the study by Rudd et al. [30], both dance groups promoted the development of inhibitory control, and the working memory capacity presented signs of improvement. Motor competence did not improve beyond typical development. No significant differences were found between the groups.

\subsection{GQ2-What Were the Results of Intervention Programs Involving Executive Functions and Digital Games?}

The study by Mondéjar et al. [31] found a clearly prominent activity at the brain's prefrontal level related to executive functions. Furthermore, it was observed that the link between cognitive abilities and certain video games mechanics is not disjointed, that is, one mechanic develops several cognitive abilities, and each skill can be developed by several mechanics. Thus, the authors established relationships between cognitive skills and the mechanics involved: general cognitive activation (precise action and logical 
puzzles); executive functions (learning patterns and logic puzzles); working memory (mime sequences, logic puzzles, and timely action); cognitive flexibility (logical puzzles and timely action); and inhibitory control (mime sequences, precise action, and pattern learning).

The research by Sánchez-Pérez et al. [32] showed a significant improvement in cognitive skills, such as non-verbal IQ and inhibition. It also demonstrated a better academic performance in math and reading skills among children who participated in the training compared to those who did not. Most of the improvements were related to training in working memory tasks.

In the study by Özçetin et al. [33], visual memory scores were slightly better in the game group. The research by Song et al. [34] demonstrated that gaming scores were significantly related to various cognitive control functions and differentiated between high and low cognitive control groups.

\subsection{GQ3-What Were the Results of Intervention Programs Involving Motor Development and Digital Games?}

The study by Sheehan et al. [35] demonstrated that the intervention group significantly improved postural stability over the 6 weeks of intervention compared to the control group from the typical physical education class. Improvements were also evidenced in the control group of the physical education class that focused on agility, balance, and coordination.

In the research by Barnett et al. [36], significant improvements were shown over time, but there was no significant difference between the groups. The intervention did not alter perceived object control.

Based on the analyses by McGlashan et al. [37], children in the intervention group significantly improved their manual dexterity scores compared to the control group.

\subsection{FQ1-What Were the Tests Used to Assess Executive Functions?}

Several tests can be used to assess working memory, cognitive flexibility, and inhibitory control. According to Diamond [8], these elements are considered basic components of executive functions.

For working memory, the study by Alesi et al. [23] used the Visual Discrimination Test, Reaction Time Test, Forward and Backward Digit Test, and Corsi Block-Tapping Test. Mondejar et al. [31] used a test adapted from the Trail Making Test (TMT); Egger et al. [25], the Backward Color Recall Task; Sánchez-Pérez et al. [32] the Digit Span Task based on the subtest of the Wechsler Intelligence Scale for Children (WISC-III) and dots task. Özçetin et al. [33] applied the Verbal Fluency Test (FAS Verbal Fluency), California Verbal Learning Test-Children's Version (CVLT-C), and Benton Visual Retention Test (BVRT); Van Der Fels et al. [28] the Digit Span Backward of the WISC-III Digit Span task, for the verbal working memory, and an adapted version of a Visuospatial Memory task, for the visuospatial working memory. Lin et al. [24] used the Modified Delayed Matching Test, which examines spatial working memory; and Rudd et al. [30] used the List Sorting Working Memory Test.

For cognitive flexibility, the research by Mondéjar et al. [26] used the Washers Test, an adaptation of the Tower of Hanoi (TOH). Egger et al. [20] chose the Flanker Task with a "mixed" block; and Rudd et al. [25] applied the Dimensional Change Card Sort (DCSS) test.

For inhibitory control, the study by Mondéjar et al. [31] used the Interference Test (an adaptation of the test of Stroop); Egger et al. [20] the Eriksen Flanker Task adapted for children [25]; Sánchez-Pérez et al. [32] the go/no go task and the dots task. Ludyga et al. [27] and Rudd et al. [30] used the Flanker Task; Özcetin et al. [28] the Stop-Signal Task and original test of Stroop. Van Der Fels et al. [28] applied a modified version of the Flanker Task for the interference control and Stop-Signal task; and Song et al. [34] used a Korean version of the Stroop Color-Word Test for Children and the Korean version of the Color Trails Test (CTT).

Some research applied tests that evaluated the three basic executive functions (cognitive flexibility, inhibitory control, and working memory) such as Alessi et al. [23], who used 
the Tower of London Test; Sánchez-Pérez et al. [32] used the Spanish version of the Kaufman Brief Intelligence Test (K-Bit); Haapala et al. [26] used the Raven's Colored Progressive Matrices for non-verbal reasoning; Özçetin et al. [33] the Trail Making Tests AB (TMT AB); and Song et al. [29] applied the Korean Wechsler Intelligence Scale for Children-Fourth Edition (K-WISC-IV-C).

Other surveys did not clearly specify which executive components were evaluated, such as Wunsch et al. [24], who used the Tower of Hanoi task, the Mosaic Task, a subtest of the Wechsler Intelligence Scale, and D2-Attention Endurance Test in Three Versions.

\subsection{FQ2-What Were the Tests Used to Assess Motor Development?}

Regarding the studies that evaluated gross motor development, Ludyga et al. [27] evaluated the gross motor skill by the Heidelberg Gross-Motor Test (HGMT). Two studies used the Körperkoordinationstest für Kinder (KTK). Egger et al. [20] measured gross motor coordination and Van Der Fels et al. [28] used three KTK items and one item from the Bruininks-Oseretsky test of Motor Proficiency, 2nd Edition (BOT-2). Barnett et al. [36] assessed object control competence through the Test of Gross Motor Development, 2nd Edition (TGMD-2). Two studies used the second edition of the Movement Assessment Battery for Children (MABC-2), however, Lin et al. [29] used it to evaluate gross motor skills and McGlashan et al. [37] to evaluate fine motor skills.

The study by Alessi et al. [23] assessed motor skills through a battery consisting of three tests: 20-m Sprint Test, Agility Test, and Standing Board Jump Test.

The research by Haalapa et al. [26] evaluated speed and agility through the $50 \mathrm{~m}$ Shuttle Run test, static balance through the Modified Flamingo Balance Test, and manual dexterity and upper limb movement speed through the Box and Block Test. Sheehan et al. [35] also assessed balance through tests on the HUR BT4 ${ }^{\mathrm{TM}}$ platform for advanced postural stability tests.

Rudd et al. [30] assessed motor competence through the Canadian Agility and Movement Skill Assessment (CAMSA). This assessment consists of 7 tasks, which must be completed in sequence as quickly and accurately as possible.

The study by Wunsch et al. [24] evaluated anticipatory motor planning. For that, the authors used three tests to measure the end-state comfort (ESC) effect, considering three different tasks: bar transport task, sword rotation task, and grasp height task.

\subsection{FQ3-How and What Were the Digital Games Used?}

Out of the seven studies that used digital games, two used serious games (type of game developed to behavioral or operational skills focused on teaching and learning strategy. [7]). The research by Mondéjar et al. [31] used a serious game set focused on specific action mechanics. These games were developed by several students of the Faculty of Computer Science in Ciudad Real (University of Castilla-La Mancha), namely: Dreamskeeper (move the mouse to avoid obstacles); KittenQuest (avoid obstacles in your way in a timely manner); CrazyFarm (show visual and sound sequences that require imitation); Api's Adventures (platform on which a particular pattern that enemies repeat must be identified to reach the next levels); and Kunoichi (plan a set of basic actions in terms of logical moves to exit the gate). The study by Song et al. [34] used CoCon for mobile devices. In this game, cognitive control skills are assessed while users play it. A total of ten games are included assessing sustained attention, working memory, inhibitory ability and response selection, and categorization. Tasks were sorted based on their difficulty levels.

Regarding active video games, two studies used interventions with exergames for six weeks. The investigation by Sheehan et al. [35] used an exergame teaching station set up on the stage of an elementary school. Participants were divided into three subgroups that alternated to a different season each day, 4 to 5 times a week. The subgroup allowed equal rotation between three stations: Dance $^{\mathrm{TM}}$, XR Board ${ }^{\mathrm{TM}} /$ Lightspace $^{\mathrm{TM}}$, and Wii Fit ${ }^{\mathrm{TM}}$ Plus. All students from the iDance ${ }^{\mathrm{TM}}$ station started at the basic levels. However, by the third week, they were able to select their own difficulty level to match their skill level. 
Lightspace ${ }^{\mathrm{TM}}$ and $\mathrm{XR}$ Board ${ }^{\mathrm{TM}}$ were combined into a single season due to the difficulty of virtual snowboarding. After two downhill races, a student would switch to Lightspace ${ }^{\mathrm{TM}}$ to give his/her legs a rest and play games that required arm activity. The investigation by Barnett et al. [36] used Nintendo Wii ${ }^{\circledR}$ sessions one hour a week after school hours. In this intervention, two consoles were provided, with four children allocated to each timeslot. Children played in pairs. Two research assistants supervised each session but were instructed not to provide skills training. Nintendo $\mathrm{Wii}^{\circledR}$ games have been specifically chosen to represent a variety of sports that require the use of object control skills. A different set of games was offered every fortnight, and children could choose.

The study by Özçetin et al. [33] considered the games that participants routinely played at home, at least $1 \mathrm{~h}$ a day, 5 times a week. To this end, the researchers classified the games into five categories: online role-playing games, online first-person shooter, real-time strategy games, action/adventure games, and survival/platform games.

The research by Sánchez-Pérez et al. [32] used 40-min computerized training sessions instead of a specific game. Therefore, each child started inside a spaceship, and there were four planets/satellites in front of him/her. Each planet/satellite represented a training task: Planet Fire represented the $n$-back task, Earth denoted math activities, Moon was the working memory span task, and Planet Ice represented the task in abstract ways. The tasks included on the Planet Fire, Moon, and Planet Ice formed the working memory training, while activities on Earth conformed to mathematical training.

Finally, the study by McGlashan et al. [37] used a custom computerized manual dexterity tapping interactive online game. Children could choose between two games, Dance Mat Typing or Typing Chef. Participants were asked to play 5 times a week for about 10 min each time for 4 weeks. In the game, children pressed a series of four keys with four different fingers from their dominant hand (index, middle, ring, and little fingers) on a keyboard. The task was divided into two conditions, random and sequential.

\subsection{SQ1-How Many and What Were the Works Applied in a School Environment?}

Of the analyzed studies, seven ( $46 \%$ ) were carried out in a school environment. Three studies were conducted during physical education classes [27,28,35]. However, the study by Ludyga et al. [27] also assessed after the school period, in leisure time. Egger et al. [25] applied in the classroom and Sánchez-Pérez et al. [32] inside the computer lab. Barnett et al. [36] conducted the study in the school environment but after school hours. Finally, Rudd et al. [30] performed the intervention during physical education classes but did not specify when.

Most of these studies found significant positive results between pre- and post-intervention. These studies reinforce the importance and effectiveness of interventions with both digital games and executive functions and motor development, considering a school environment in an ecological approach.

\subsection{SQ2-What Is the Distribution of Articles by Continent?}

To identify the countries where the works were developed, the institution of origin of the authors of each article, the place of application of the practical tests, and direct references to the country in the text were considered.

It was possible to notice a varied distribution between different countries. Most studies were focused on Europe. Regarding the continents, eight studies (60\%) were performed in Europe (Germany (2), Switzerland, Netherlands, Finland, Italy, and Spain (2)), three publications (20\%) were in Asia (Taiwan, South Korea, and Turkey), two publications (14\%) in Oceania (Australia (2)), and one publication (6\%) in North America (Canada).

\subsection{SQ3-What Are the Perceived Trends?}

Figure 2 shows the frequency of publications on the subject, which began to be explored in 2013 and had its peak of scientific production in 2019. 


\section{Legend}
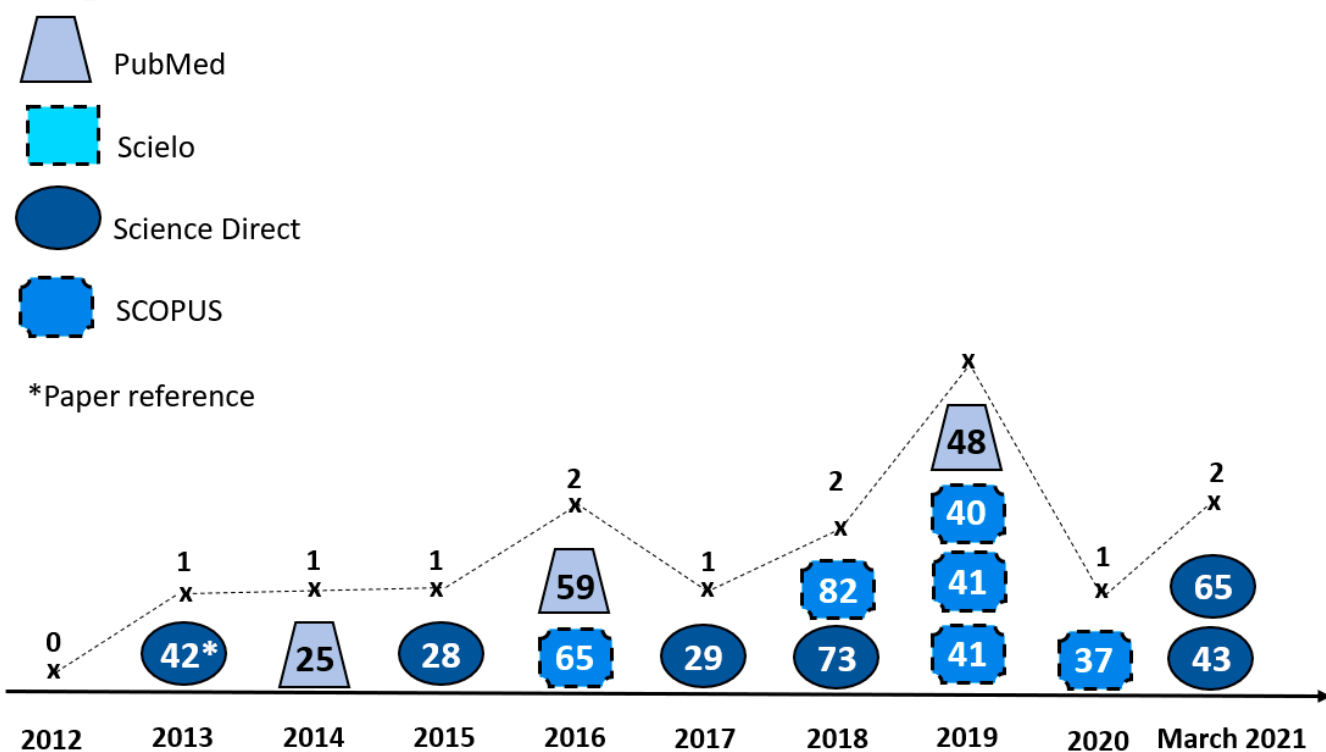

Figure 2. Frequency of publications and databases.

The databases with the most publications were Scopus and Science Direct, accounting for $80 \%$ of the total, validating the effectiveness of these databases. PubMed, a reference database in the health area, accounted only for $20 \%$ of the studies, and Scielo had no articles identified in the process.

Trends in "terms" were identified through bibliometric mapping [38], performed on the VOSViewer tool. Figure 3 shows the density of terms and the formation of clusters of interest, grouped by colors according to the proximity of the terms. The identified clusters are presented and characterized below:

- Green: houses the term "children", the most prominent among all clusters, therefore, the term with the highest occurrence in all 15 articles.

- Light blue: just one term, related to cognitive abilities.

- Purple: term on cognition that enters the yellow group.

- Yellow: cluster centered on school-aged children.

- Dark blue: involves executive functions and exercise.

- Red: related to cognition and technology.

cognitive abilities

$$
\text { children }
$$

cognitive functions school children

exergaming acute exercise

executive functions

Figure 3. Cluster density map.

Figure 4 provides an overview of the connections between terms in the same or different clusters. The pairs and strength of connection of these relations are determined by factors such as the occurrence of terms in all imported articles and the number of articles with the same database source or authorship [39]. This model represents the overlapping of chronological incidence of terms on the cluster map. The most recent term 
detected by the tool was "cognitive functions", which, within the same cluster, is related to cardiorespiratory and motor exercises and obesity.

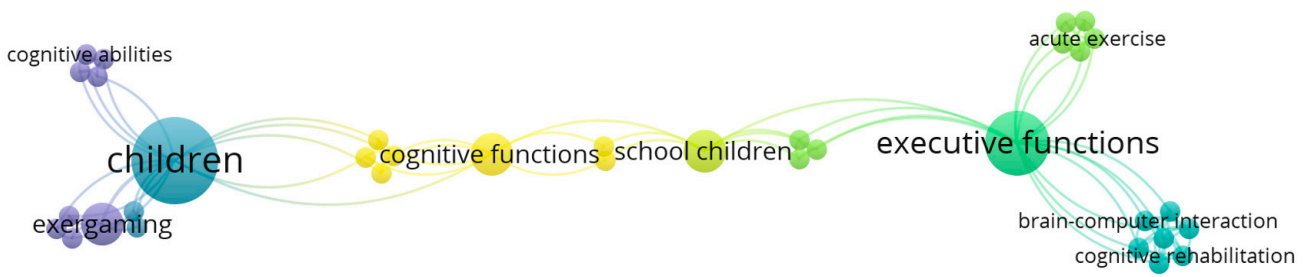

@ VOSviewer

Figure 4. Overview of the relationship among terms.

In addition, the global view shows the composition of the terms used in the research. Children and executive functions are somehow related to most terms. However, exercises and technology showed no links.

From the analysis of the resulting studies, no studies with a direct relationship among the three themes focused on this research were found. Although the research string was divided to broaden the results, a significant number of articles were not found. It was possible to notice that the continent with the highest number of studies was Europe, demonstrating a research gap in other continents.

Studies involving executive functions and motor development have mostly been shown to be effective. The same occurred with those studies involving executive functions and digital games, and motor development and digital games. Moreover, it is possible to affirm that the executive functions and motor skills are stimulated by common underlying processes $[9,10]$, and studies pointed out that digital games can aid in the stimulation processes. It led us to reflect on the studies in the sense of integrating the three themes. Executive functions and motor development interventions could have digital games as cognitive involvement. In interventions of executive functions and digital games, games mechanics [31] also apply to the real world, to psychomotor games, for instance. Mondejár et al. [31] used games that also demanded motor coordination. Motor development and digital games interventions assessed elements such as coordination and balance, which were also evaluated in studies involving executive functions [23-25] and presented positive results.

In relation to the research profile, the average age of the surveyed children was 9 years old, demonstrating that most interventions were applied to children in the final grades of elementary school. Wunsch et al. [24] and Barnett et al. [36] documented that the older the children were, the more they presented significant results. The age group could be one of the explanations for $87 \%$ of the articles demonstrating significant positive results in the experimental groups.

Regarding the duration of the interventions, the shortest one lasted one session, which, according to Egger et al. [25], may not be effective. However, Wunsch et al. [24] and Mondejár [31], who also used only one session, found positive results. Only two studies were longitudinal [26,32], so it was not possible to measure the long-term effectiveness of the interventions. In this way, the type and duration of the intervention added to the age of the children and the combined use of the stimulation of executive functions and motor development, associated with digital games, seems to constitute an emerging research topic. 


\section{Conclusions}

This work identified the current state of research involving interventions related to executive functions, motor development, and digital games for children. The systematic mapping made it possible to identify and analyze the articles selected in this study.

The study identified a growing interest in the topic. Still, the studies are heterogeneous in relation to the duration of interventions, analyzed executive functions and motor skills, applied tests, and games.

Based on the results, most studies showed significant positive effects regarding the interventions. Some point out that physically active children demonstrated better executive functioning when compared to sedentary children.

Furthermore, activities involving some type of motor skills were more related to some executive functions. In particular, this element is noticed when they share common underlying processes, such as coordination activities, which are more related to working memory and inhibitory control.

Regarding executive functions and digital games, serious games and commercial video games seem to stimulate cognitive processes. Research also shows that programs involving video games that stimulate executive functions improved school performance.

Less than half of the studies (46\%) performed their interventions in a school environment.

Considering the research field of this work, it is considered to have the following strengths demonstrating the research gaps: (1) initial evidence that studies in this research field using executive functions, motor development, and digital games aimed at children with applications in ecological environments, specifically in the school context, is still incipient, and (2) there is also no research that takes into account executive functions, motor development, and digital games simultaneously. Finally, this investigation identified a gap in the area of neurocognitive, motor, and digital games that stimulate executive functions and motor development in children in the school context. As future work, these criteria should be combined in a school neuropsychological and motor intervention using digital games, which should be carried out to discover their effects and effectiveness in this target group. For this, new studies should be performed, including other databases in the research process.

Finally, despite attempts to mitigate risks, certain choices may have affected the outcome of this systematic mapping. The choice of databases is a risk factor. To cover more results, four databases were selected. However, the results showed that certain databases were ineffective, such as Scielo. The study did not include the database Web of Science. The generalization of the terms used in the research process (related to executive functions, children, and video game), inclusion and exclusion criteria, in addition to the authors' assessment of the relevance, also delimited the results, possibly excluding relevant articles. We sought to minimize these risks by following the methodology of Keshav [22] and Petersen et al. [21].

Author Contributions: Conceptualization, V.B.M., D.N.F.B., G.R.S. and J.L.V.B.; methodology, V.B.M., D.N.F.B., G.R.S., J.L.V.B., D.R.F.L. and V.R.Q.L.; software, V.B.M., D.N.F.B.; validation, V.B.M., D.N.F.B., G.R.S., J.L.V.B., D.R.F.L. and V.R.Q.L.; formal analysis, V.B.M., D.N.F.B., G.R.S., J.L.V.B., D.R.F.L. and V.R.Q.L.; investigation, V.B.M., D.N.F.B. and G.R.S.; resources, J.L.V.B., D.R.F.L. and V.R.Q.L.; data curation, V.B.M. and D.N.F.B.; writing-original draft preparation, V.B.M., D.N.F.B. and G.R.S.; writing-review and editing, J.L.V.B., D.R.F.L. and V.R.Q.L.; visualization, V.B.M. and D.N.F.B.; supervision, D.N.F.B., G.R.S. and J.L.V.B.; project administration, V.B.M.; funding acquisition, V.R.Q.L. All authors have read and agreed to the published version of the manuscript.

Funding: This research was funded by national funds through the Fundação para a Ciência e a Tecnologia, I.P. (Portuguese Foundation for Science and Technology) by the project UIDB/05064/2020 (VALORIZA-Research Centre for Endogenous Resource Valorization) and it was partially supported by Fundação para a Ciência e a Tecnologia under Project UIDB/04111/2020, and ILIND-Instituto Lusófono de Investigação e Desenvolvimento, under projects COFAC/ILIND/COPELABS/1/2020 and COFAC/ILIND/COPELABS/3/2020. 
Institutional Review Board Statement: Not applicable.

Informed Consent Statement: Not applicable.

Data Availability Statement: Not applicable.

Acknowledgments: The authors would like to thank the Feevale University (Feevale), the University of Vale do Rio dos Sinos (Unisinos), the Research Support Foundation of the State of Rio Grande do Sul (FAPERGS), the National Development Council Scientific and Technological (CNPq), and the Coordination for the Improvement of Higher Education Personnel-Brazil (CAPES)—Code Funding 001.

Conflicts of Interest: The authors declare no conflict of interest.

\section{References}

1. Roebers, C.M.; Kauer, M. Motor and Cognitive Control in a Normative Sample of 7-Year-Olds. Dev. Sci. 2009, 12, 175-181. [CrossRef] [PubMed]

2. Jaakkola, T.; Yli-Piipari, S.; Huotari, P.; Watt, A.; Liukkonen, J. Fundamental Movement Skills and Physical Fitness as Predictors of Physical Activity: A 6-Year Follow-up Study. Scand. J. Med. Sci. Sport. 2016, 26, 74-81. [CrossRef]

3. Schmidt, M.; Egger, F.; Benzing, V.; Jäger, K.; Conzelmann, A.; Roebers, C.M.; Pesce, C. Disentangling the Relationship between Children's Motor Ability, Executive Function and Academic Achievement. PLoS ONE 2017, 12, e0182845. [CrossRef]

4. $\quad$ Geertsen, S.S.; Thomas, R.; Larsen, M.N.; Dahn, I.M.; Andersen, J.N.; Krause-Jensen, M.; Korup, V.; Nielsen, C.M.; Wienecke, J.; Ritz, C.; et al. Motor Skills and Exercise Capacity Are Associated with Objective Measures of Cognitive Functions and Academic Performance in Preadolescent Children. PLoS ONE 2016, 11, e0161960. [CrossRef]

5. Whitherspoon, H.L.; Sanders, S. Active Gaming: A new paradigm in childhood physical activity. Digital Culture E Education. 2011. Available online: https:/ / www.digitalcultureandeducation.com/volume-32-papers/active-gaming-the-new-paradigmin-childrens-physical-activity (accessed on 8 February 2022).

6. Cruz, V.T.; Pais, J.; Bento, V.; Mateus, C.; Colunas, M.; Alves, I.; Coutinho, P.; Rocha, N. A Rehabilitation Tool Designed for Intensive Web-based Cognitive Training: Description and usability study. JMIR Res. Protoc. 2013, 2, 59. [CrossRef]

7. Paiva, N.M.N.; Costa, J.S. A Influência Da Tecnologia Na Infância: Desenvolvimento Ou Ameaça? Psicologia.pt 2015, 1, 1-13.

8. Diamond, A. Executive Functions. Annu. Rev. Psychol. 2013, 64, 135-168. [CrossRef]

9. Diamond, A. Close Interrelation of Motor Development and Cognitive Development and of the Cerebellum and Prefrontal Cortex. Child Dev. 2000, 71, 44-56. [CrossRef]

10. Livesey, D.; Keen, J.; Rouse, J.; White, F. The Relationship between Measures of Executive Function, Motor Performance and Externalising Behaviour in 5- and 6-Year-Old Children. Hum. Mov. Sci. 2006, 25, 50-64. [CrossRef]

11. Diamond, A. Effects of Physical Exercise on Executive Functions: Going beyond Simply Moving to Moving with Thought. Physiol. Behav. 2015, 176, 139-148.

12. Barbosa, D.N.F.; Bassani, P.B.; Mossmann, J.B.; Schineider, G.T.; Reategui, E.; Branco, M.A.A.; Meyrer, L.S.; Nunes, M. Mobile Learning and Games: Experiences with Mobile Games Development for Children and Teenagers Undergoing Oncological Trearment. In Proceedings of the Internacional Conference on Serious Games, Berlin, Germany, 9-10 October 2014; pp. 153-316.

13. Di Tore, P.A.; Raiola, G. Exergames in Motor Skill Learning. J. Ofphysical Educ. Sport 2012, 12, 358.

14. Cerqueira, B.B.; Barbosa, D.F.F.; Mossmann, J.B.; Cardoso, C.O. Inhibitory Control Stimulation in Elementary School Children Though Digital Games: A Systematic Mapping Study. Appl. Neuropychol.-Child 2020, 1-12. [CrossRef]

15. Zimmermann, N.; De Oliveira Cardoso, C.; Kochhann, R.; Jacobsen, G.; Fonseca, R.P. Contributions of the Ecological Approach to the Neuropsychology of Executive Functions. Temas Psicol. 2014, 22, 639-654. [CrossRef]

16. Berlese, D.; Ferrari Barbosa, D.N.; Mossmann, J.B.; Theisen Schneider, G.T.S.; Benites, B. GameMove: A Proposal for Evaluation of Motor Development in Children Mediated by Digital Games. Int. J. Innov. Educ. Res. 2020, 8, 169-177. [CrossRef]

17. Johnson, K.; Pavleas, J.; Chang, J. Kinecting to Mathematics through Embodied Interactions. Computer 2013, 46, 101-104. [CrossRef]

18. McClelland, M.M.; Cameron, C.E. Developing Together: The Role of Executive Function and Motor Skills in Children's Early Academic Lives. Early Child. Res. Q. 2019, 46, 142-151. [CrossRef]

19. Mossmann, J.B. Um Exergame Para Estimulacao de Componentes Das Funcoes. 2016, pp. 369-376. Available online: http://www. sbgames.org/sbgames2016/downloads/anais/157307.pdf (accessed on 8 February 2022).

20. De Cardoso, C.O.; Zimmermann, N.; Paraná, C.B.; Gindri, G.; De Pereira, A.P.A.; Fonseca, R.P. Brazilian Adaptation of the Hotel Task A Tool for the Ecological Assessment of Executive Functions. Dement. Neuropsychol. 2015, 9, 156-164. [CrossRef]

21. Petersen, K.; Vakkalanka, S.; Kuzniarz, L. Guidelines for Conducting Systematic Mapping Studies in Software Engineering: An Update. Inf. Softw. Technol. 2015, 64, 1-18. [CrossRef]

22. Keshav, S. How to Read a Paper. Key Top. Surg. Res. Methodol. 2007, 37, 545-555. [CrossRef]

23. Alesi, M.; Bianco, A.; Padulo, J.; Vella, F.P.; Petrucci, M.; Paoli, A.; Palma, A.; Pepi, A. Motor and Cognitive Development: The Role of Karate. Muscles Ligaments Tendons J. 2014, 4, 114-120. [CrossRef] 
24. Wunsch, K.; Pfister, R.; Henning, A.; Aschersleben, G.; Weigelt, M. No Interrelation of Motor Planning and Executive Functions across Young Ages. Front. Psychol. 2016, 7, 1031. [CrossRef]

25. Egger, F.; Conzelmann, A.; Schmidt, M. The Effect of Acute Cognitively Engaging Physical Activity Breaks on Children's Executive Functions: Too Much of a Good Thing? Psychol. Sport Exerc. 2018, 36, 178-186. [CrossRef]

26. Haapala, E.A.; Lintu, N.; Väistö, J.; Tompuri, T.; Soininen, S.; Viitasalo, A.; Eloranta, A.M.; Venäläinen, T.; Sääkslahti, A.; Laitinen, T.; et al. Longitudinal Associations of Fitness, Motor Competence, and Adiposity with Cognition. Med. Sci. Sports Exerc. 2019, 51, 465-471. [CrossRef] [PubMed]

27. Ludyga, S.; Koutsandréou, F.; Reuter, E.M.; Voelcker-Rehage, C.; Budde, H. A Randomized Controlled Trial on the Effects of Aerobic and Coordinative Training on Neural Correlates of Inhibitory Control in Children. J. Clin. Med. 2019, 8, 184. [CrossRef]

28. Van der Fels, I.M.J.; te Wierike, S.C.M.; Hartman, E.; Elferink-Gemser, M.T.; Smith, J.; Visscher, C. The Relationship between Motor Skills and Cognitive Skills in 4-16 Year Old Typically Developing Children: A Systematic Review. J. Sci. Med. Sport 2015, 18, 697-703. [CrossRef] [PubMed]

29. Lin, C.C.; Hsieh, S.S.; Chang, Y.K.; Huang, C.J.; Hillman, C.H.; Hung, T.M. Up-Regulation of Proactive Control Is Associated with Beneficial Effects of a Childhood Gymnastics Program on Response Preparation and Working Memory. Brain Cogn. 2021, 149, 105695. [CrossRef]

30. Rudd, J.; Buszard, T.; Spittle, S.; O'Callaghan, L.; Oppici, L. Comparing the Efficacy (RCT) of Learning a Dance Choreography and Practicing Creative Dance on Improving Executive Functions and Motor Competence in 6-7 Years Old Children. Psychol. Sport Exerc. 2021, 53, 101846. [CrossRef]

31. Mondéjar, T.; Hervás, R.; Johnson, E.; Gutierrez, C.; Latorre, J.M. Correlation between Videogame Mechanics and Executive Functions through EEG Analysis. J. Biomed. Inform. 2016, 63, 131-140. [CrossRef]

32. Sánchez-Pérez, N.; Castillo, A.; López-López, J.A.; Pina, V.; Puga, J.L.; Campoy, G.; González-Salinas, C.; Fuentes, L.J. ComputerBased Training in Math and Working Memory Improves Cognitive Skills and Academic Achievement in Primary School Children: Behavioral Results. Front. Psychol. 2018, 8, 2327. [CrossRef]

33. Özçetin, M.; Gümüstas, F.; Çag, Y.; Gökbay, I.Z.; Gökbay, A. The Relationships between Video Game Experience and Cognitive Abilities in Adolescents. Neuropsychiatr. Dis. Treat. 2019, 15, 1171-1180. [CrossRef]

34. Song, H.; Yi, D.J.; Park, H.J. Validation of a Mobile Game-Based Assessment of Cognitive Control among Children and Adolescents. PLoS ONE 2020, 15, e0230498. [CrossRef]

35. Sheehan, D.P.; Katz, L. The Effects of a Daily, 6-Week Exergaming Curriculum Onbalanceinfourthgrade Children. J. Sport Health Sci. 2013, 2, 131-137. [CrossRef]

36. Barnett, L.M.; Ridgers, N.D.; Reynolds, J.; Hanna, L.; Salmon, J. Playing Active Video Games May Not Develop Movement Skills: An Intervention Trial. Prev. Med. Rep. 2015, 2, 673-678. [CrossRef] [PubMed]

37. McGlashan, H.L.; Blanchard, C.C.V.; Nicole, J.S.; Lee, R.; French, B.; Sycamore, N.J. Improvement in Children's Fine Motor Skills Following a Computerized Typing Intervention. Hum. Mov. Sci. 2017, 56, 29-36. [CrossRef] [PubMed]

38. Gomes, J.Z.; Barbosa, J.L.V. Research Clusters of Ubiquitous Intelligent Services to Vehicular Users. In Proceedings of the 24th Brazilian Symposium on Multimedia and the Web, Salvador, Brazil, 16-19 October 2018; pp. 65-68. [CrossRef]

39. Van Eck, N.J.; Waltman, L. Software Survey: VOSviewer, a Computer Program for Bibliometric Mapping. Scientometrics 2010, 84, 523-538. [CrossRef] [PubMed] 